\section{$\underset{\substack{\text { hommes } \\ \text { \& migrations }}}{ }$}

\section{Hommes \& migrations}

Revue française de référence sur les dynamiques

migratoires

$1315 \mid 2016$

Ondes de choc

\title{
Penser à partir des événements de 2015 et débattre
}

\section{Abdelhafid Hammouche}

\section{CpenEdition \\ Journals}

\section{Édition électronique}

URL : http://journals.openedition.org/hommesmigrations/3704

DOI : 10.4000/hommesmigrations.3704

ISSN : 2262-3353

\section{Éditeur}

Musée national de l'histoire de l'immigration

\section{Édition imprimée}

Date de publication : 1 juillet 2016

Pagination : 6-7

ISBN : 978-2-919040-36-0

ISSN : $1142-852 X$

\section{Référence électronique}

Abdelhafid Hammouche, "Penser à partir des événements de 2015 et débattre », Hommes \& migrations [En ligne], 1315 | 2016, mis en ligne le 01 juillet 2019, consulté le 04 janvier 2020. URL http://journals.openedition.org/hommesmigrations/3704; DOI : 10.4000/hommesmigrations.3704 


\section{PENSER À PARTIR DES ÉVÉNEMENTS DE 2015 ET DÉBATTRE}

Par ABDELHAFID HAMMOUCHE, sociologue, professeur des universités, université de Lille-1, Clersé-CNRS (UMR 8019).

Les tueries de janvier et novembre 2015 en France, comme les attentats de 2016, ont suscité des réactions d'une rare ampleur et ont été suivies de nombreuses et de diverses analyses, ainsi que de grandes manifestations où s'affichaient notamment l'attachement au débat contradictoire. Les interprétations de ces événements furent multiples, depuis celles qui soulignent la diffusion d'un islam radical à celles qui interrogent les causalités sociales et l'état de la société française. Les chercheur(e)s y ont participé évidemment. Le rapport « Recherches sur les radicalisations, les formes de violence qui en résultent et la manière dont les sociétés les préviennent et s'en protègent ", remis à M. Thierry Mandon en mars 2016, rappelle d'ailleurs les initiatives des opérateurs (CNRS, ANR, universités...) et souligne le développement récent des recherches sur ces différents thèmes, prolongeant parfois des travaux anciens ${ }^{1}$. Il y apparaît que l'intérêt scientifique des chercheurs pour les thématiques liées à la radicalisation a commencé à s'affirmer dès le début des années 1980, autour des questions de violences urbaines notamment. Cette dynamique implique différents groupes de chercheurs : les " seniors " qui ont investi, parfois depuis plus de trente ans, les questions de violence, de radicalisation, de terrorisme, ou qui travaillent de longue date sur le Proche-Orient; de jeunes chercheurs qui prolongent leurs travaux depuis leurs doctorats ; sans oublier des chercheurs spécialistes d'autres champs qui se sont réorientés vers ces thématiques, en particulier depuis les années 2000. Le développement de la recherche dans ces domaines s'accompagne de l'apport des études aréales, avec la volonté de se dégager de l'orientalisme, au sens d'Edward Said, qui continue, selon le rapport, à être diffusé par les médias. Le présent numéro d'Hommes \& Migrations s'inscrit dans le prolongement de ce temps fort de réflexion sur le présent et l'avenir de notre société, et tâche de reprendre quelques-unes des questions débattues par une analyse qui se veut distanciée, reposant sur des travaux récents. Il traite de la difficulté de nommer ces événements et, ainsi, d'orienter le questionnement, mais aussi des relations établies explicitement ou non avec l'immigration et le contexte social des banlieues. La crainte d’amalgamer ou de généraliser et, plus largement, 
les précautions souvent mises en avant lors de ces sanglantes années imposent une réflexion sur les modalités de l'entrée et de la diffusion de ces discours dans l'espace public. Cet exercice de formulation prend une importance singulière eu égard aux invites faites explicitement ou implicitement à des catégories supposées plus concernées (intellectuels, leaders issus de l'immigration...).

Mais la complexité qui en ressort ne se limite pas à cette injonction à s'engager ou à une question sémantique. À l'art délicat de nommer et de délimiter le propos, s'ajoute la dimension épistémologique. Il est vrai que c'est un problème récurrent, se reposant à chaque événement marquant. Le défi n'est pas seulement dans la distanciation, logiquement mise à l'épreuve pour des intellectuels se voulant impliqués dans la cité, que dans le risque d'une tentation de démarche encyclopédique. Celle-ci ne serait pas illégitime en soi si l'on considère ces assassinats et les manifestations qui les ont suivis comme des faits sociaux totaux, et si on les prend comme analyseurs de la société française telle qu'elle se donne à voir à ce momentlà. À l'inverse, la rigueur qui réduirait les événements aux seuls individus directement impliqués et aux assassinats ne serait guère plus pertinente. Elle reviendrait à ignorer le retentissement médiatique, politique, et leurs effets difficilement mesurables auprès des citoyens. Il faut donc baliser en postulant que les processus en question relèvent aussi bien de la longue histoire du fait religieux et de sa gestion publique, que de la non moins longue histoire de l'école ou de celle de l'action publique censée combattre les inégalités et les discriminations, sans oublier évidemment celle de l'espace politique. À défaut d'une impossible perspective aussi large pour une revue, ce dossier se limite à approcher, d'une part, le débat public par la presse, par le regard porté sur de tels événements depuis l'étranger, et, d'autre part, par la mise en question du lien entre immigration et terrorisme, de celle du parcours d'enfants d'immigrés et de la relation avec le djihadisme.
Concernant le débat public, Carine Guérandel et Éric Marlière analysent un ensemble d'articles publiés par Le Monde entre le 14 novembre 2015 et le 31 mars 2016. Ils sélectionnent des articles qu'ils répartissent en trois types et discutent ensuite chacun de ces types pour mettre en relief les points saillants et les points aveugles. L'analyse des médias est prolongée par Diego Landivar, Émilie Ramillien et Marco Dell'Omodarne qui proposent de questionner le traitement médiatique des attentats entre janvier 2015 et janvier 2016 à partir de six titres de presse français. Ils s'intéressent à l'activité « de mise en production du terrorisme " pour éclairer les processus de construction médiatiques avec une enquête reposant sur 1852 articles recueillis sur le web. Gilles Gauthier nous invite à un détour et nous livre quelques extraits pour restituer les débats au Québec qui ont suivi les attentats de janvier 2015 à Paris.

L'autre entrée de ce dossier est la relation entre immigration et plusieurs phénomènes qui lui sont plus ou moins explicitement associés. S'appuyant sur des informations et des réflexions issues des médias et des sciences sociales, ainsi que sur des entretiens avec des personnes dont le profil éclaire l'engagement radical d'individus issus de l'immigration, Jean-Baptiste Meyer l'aborde sous l'angle du lien entre migration et terrorisme islamiste. Emmanuel Jovelin interroge cette relation avec la trajectoire de Mohamed Merah, en repérant les moments décisifs qui l'ont fait basculer dans la violence et en s'appuyant sur les théories de la déviance pour les analyser. La relation entre immigration, dynamiques sociales et action publique est traitée par Abdelhafid Hammouche, à partir de travaux portant sur les situations migratoires, pour mettre en relief les changements, aussi bien dans la mise en débat du fait migratoire que dans la définition de l'action publique dans les banlieues. Un entretien auprès de Jacques Toubon, Défenseur des droits, complète cette contextualisation par l'analyse des disciminations tant sur le registre législatif que celui des dispositifs publics. 